\title{
Cigarette smoking associated with chronic pancreatitis: a case control study in China
}

Yamin Lai ${ }^{1}$, Hong Yang ${ }^{1}$, Wei Han ${ }^{2}$, Tao Guo ${ }^{1}$, Hong LV ${ }^{1}$, Jingnan Li ${ }^{1}$ and Jia-Ming Qian ${ }^{*}$

\begin{abstract}
Background: Chronic pancreatitis (CP) is a long-term inflammatory disease affecting the pancreas. No studies are currently available associating cigarette smoking with CP in Chinese mainland population. This study aims to assess the evidence for tobacco smoking as a risk factor for $\mathrm{CP}$ and to find the dose-response relationship between them precisely in Chinese mainland population.

Methods: This retrospective study enrolled Chinese patients with CP and control patients at the Peking Union Medical College Hospital from 1983 to 2008. Demographic and clinical data were collected, and Chi-square $\left(x^{2}\right)$ test and a Cox proportional hazards regression model were used for statistical analysis. This study evaluated whether cigarette smoking is a risk factor for CP in 346 patients and 346 healthy controls (CP group: 267 males, 79 females; control group: 270 males, 76 females) with mean ages of 49 and 49.2 years, respectively.

Results: In the CP group, 46.8\% were smokers, and $41 \%$ were drinkers. Heavy smokers ( $\geq 20$ cigarettes/d), who were either male $(P=0.03)$ or older than 30 years $(P=0.045)$, or males older than 30 years $(P=0.021)$, were significantly more prone to CP than light smokers. CP patients, regardless of their gender, who had smoked for more than 30 years and were without biliary disease had a significantly higher risk to develop CP compared with health control group $(\mathrm{OR}=2.35,95 \% \mathrm{Cl}: 1.106-4.973, P=0.026)$. There was no statistically significant association between smoking duration of less than 30 years and the risk of CP regardless of gender, age, or biliary disease.

Conclusions: Cigarette smoking is an important risk factor for CP in the Chinese population and correlates with risk factors, such as age, gender, biliary disease, and alcohol consumption. In conclusion, cigarette smoking is an important risk factor for $\mathrm{CP}$ in the Chinese subpopulation.
\end{abstract}

Keywords: Chronic pancreatitis, Chinese population, Smoking, Drinking, Risk factor

\section{Background}

Chronic pancreatitis (CP) is an inflammatory disease of the pancreas, which markedly increases the risk of pancreatic cancer. The progressive inflammation, necrosis/ apoptosis, and duct obstruction lead to fibrotic destruction of pancreatic glandular parenchyma and result in impaired secretory function. The incidence of $\mathrm{CP}$ is approximately 7 to 10 per 100,000 annually in Europe [1]. The incidence and mortality of pancreatitis are on the rise in recent years in Europe [2] and Japan [3]. A recent retrospective study of 346 cases of $\mathrm{CP}$ at the

\footnotetext{
*Correspondence: qianjiaming1957@126.com; QJMqjiaming1957@126.com 'Department of Gastroenterology, Chinese Academy of Medical Sciences and Peking Union Medical College, Peking Union Medical College Hospital, 1 Shuai Fu Yuan, Beijing 100730, China

Full list of author information is available at the end of the article
}

Peking Union Medical College Hospital, China, from 1983 to 2008 revealed that the number of CP patients and the proportion of $\mathrm{CP}$ cases in the entire hospitalized inpatient population increased rapidly from 1983 to 2008 [4].

Etiological risk factors for $\mathrm{CP}$ include alcohol consumption, smoking status, nutrition, genetic mutations, ductal obstruction, and autoimmunity [5-10]. Alcohol consumption has been considered as the primary cause of acute and chronic pancreatitis [11-15]. Approximately, a third of all the cases of acute pancreatitis and 60 to $90 \%$ of $\mathrm{CP}$ in the United States and other developed countries are attributed to alcohol intake [16].

Recent studies showed that cigarette smoking is another important risk factor, which is closely associated with CP [17, 11, 18-21]. The effect of cigarette smoking on CP was first reported in 1994 [22]. The study showed 
that heavy smokers had a higher occurrence of pancreatic calcifications. The risk of calcification in smokers was 1.21 fold higher compared with nonsmokers. After 17 years of follow-up, the study found that 277 smokers (69\%) with $\mathrm{CP}$ had developed calcifications compared with only 93 nonsmokers (55\%) with CP. Another study showed that cigarette smoking significantly increased the risk of pancreatic calcification in late-onset idiopathic $\mathrm{CP}$ in nondrinking population [20]. In late-onset idiopathic CP, smokers developed pancreatic calcification faster and more frequently compared with nonsmokers. The association between smoking and pancreatic calcification was independent of gender, body mass index, and exocrine or endocrine insufficiency [20].

Animal studies showed that smoking enhanced the effect of ethanol on CP [23]. Alcohol consumption and cigarette smoking are common risk factors in China. However, currently no studies in the English literature are available reporting a significant association between alcohol consumption and cigarette smoking and development of $\mathrm{CP}$ in the Chinese population. The aims of this study were to determine the role of cigarette smoking as a risk factor in this population as well as to analyze its interaction with other known risk factors for $\mathrm{CP}$. A retrospective case-control study was conducted to analyze smoking and alcohol consumption status in this population, and to determine whether cigarette smoking and alcohol consumption were associated with $\mathrm{CP}$.

\section{Methods}

\section{Study population}

In this retrospective case-control study, data from 346 consecutive cases of $\mathrm{CP}$ enrolled in the local hospital, from January 1983 to January 2008, were analyzed. The diagnostic criteria for CP were based on the 2000 Asia-Pacific consensus report on CP [24]. The $\mathrm{CP}$ diagnosis was established based on clinical history, classic biochemical alterations, functional tests, and typical ultrasound-radiological and endoscopic retrograde cholangiopancreatography (ERCP). All patients and controls were 18 years or older. Patients who had pancreatic tumors, such as pancreas cancer or intraductal papillary mucinous neoplasm (IPMN), were excluded from this study. Ageand gender-matched healthy individuals (346) were randomly selected from the PUMCH Medical Center as control group. All controls had no history of biliary or pancreatic diseases. Written, informed consent was obtained from all individuals enrolled in this study. The study protocol was reviewed and approved by the Institutional Review Committees of Beijing Union Medical College Hospital. Further information on the study design and participant characteristics can be found elsewhere [4].

\section{Demographic and clinical data collection}

Demographic and clinical data, including age, gender, height, body weight, body surface area, body mass index (BMI), history of smoking, number of cigarettes smoked daily, years of drinking and smoking, history of biliary disease, and other clinical data, was collected from all patients and controls. Smoking intensity was calculated as the average number of cigarettes smoked per day over a lifetime (cigarettes per day). The duration of cigarette smoking was calculated as years of smoking. The cumulative amount of smoking (cigarette-years) was calculated from the smoking history by multiplying the years of smoking by the average number of cigarettes smoked daily. Drinking status is that if the patient has a history of alcohol consumption for more than 10 years. Alcohol intake (grams per month) was expressed as grams of alcohol consumption per month. Drinking duration was calculated as years of drinking (drinking years). Alcohol consumption is a roughly calculation of total alcohol compumtion through Alcohol intake (grams per month) multiply by Drinking duration (drinking years) In another word: Alcohol consumption = Alcohol intake (grams per month)x Drinking duration (drinking years).

\section{Statistical analysis}

The SPSS 13.0 software (IBM Corporation, Chicago, IL, USA) was used for all statistical analyses. Differences in mean values or frequency distributions between CP cases and controls were examined by an unpaired Student's $t$ test or Chi-square $\left(\chi^{2}\right)$ test. Cox proportional hazards regression analysis was used to calculate multivariable-adjusted odds ratios (ORs) and 95\% confidence intervals (CIs) for CP in relation to cigarette smoking. The ORs were adjusted for potentially confounding variables, such as age, gender, biliary disease, and alcohol consumption. $P$ values $<0.05$ were considered statistically significant.

\section{Results \\ Patient characteristics}

A total of 346 patients with $\mathrm{CP}$ and 346 healthy individuals were included in this retrospective case-control study (Table 1). There were 267 males and 79 females in the $\mathrm{CP}$ group, and 270 males and 76 females in the control group. The mean ages were 48.97 years and 49.16 years, respectively. The BMIs were $22.46 \pm 13.52$ and $24.59 \pm 3.29 \mathrm{~kg} / \mathrm{m}^{2}$, respectively. Nearly half of the subjects were former or current smokers $(46.8 \%$ in the $\mathrm{CP}$ group and $48.8 \%$ in the control group). The percentage of smokers among $\mathrm{CP}$ patients was comparable to that of the controls. The majority of smokers smoked more than 20 cigarettes daily in both groups, but significantly more $\mathrm{CP}$ patients smoked more than 20 cigarettes per day (32 vs. $24 \%, P=0.01$ ). 
Table 1 Clinical demographics of chronic pancreatitis patients $(n=346)$ and controls $(n=346)$ in a retrospective case-control study

\begin{tabular}{|c|c|c|c|c|c|}
\hline \multirow[t]{2}{*}{ Variable } & \multicolumn{2}{|c|}{ Chronic Pancreatitis } & \multirow{2}{*}{$\begin{array}{l}\text { Control } \\
\text { number }\end{array}$} & \multirow[b]{2}{*}{ percent } & \multirow[t]{2}{*}{$P$ value } \\
\hline & number & percent & & & \\
\hline All subjects & 346 & & 346 & & \\
\hline Age (mean $\pm S D$, years) & $48.97 \pm 14.11$ & & $49.16 \pm 14.40$ & & \\
\hline$<30$ (years) & 28 & $8.10 \%$ & 29 & $8.40 \%$ & 0.89 \\
\hline$\geq 30$ (years) & 318 & $91.90 \%$ & 317 & $91.00 \%$ & \\
\hline \multicolumn{6}{|l|}{ Gender } \\
\hline Male & 267 & $77.17 \%$ & 270 & $78.03 \%$ & 0.784 \\
\hline Female & 79 & $22.83 \%$ & 76 & $21.97 \%$ & \\
\hline Body mass index $\left(\mathrm{kg} / \mathrm{m}^{2}\right)$ & $22.46 \pm 13.5$ & & $24.59 \pm 3.29$ & & \\
\hline 10-18.5 & 26 & $8 \%$ & 46 & $13.29 \%$ & 0.018 \\
\hline$\geq 18.5$ & 110 & $32 \%$ & 83 & $23.99 \%$ & \\
\hline \multicolumn{6}{|l|}{ Smoking duration (years) } \\
\hline$<20$ & 236 & $68.21 \%$ & 245 & $70.81 \%$ & 0.001 \\
\hline $20-30$ & 58 & $16.76 \%$ & 78 & $22.54 \%$ & \\
\hline$>30$ & 52 & $15.03 \%$ & 23 & $6.65 \%$ & \\
\hline \multicolumn{6}{|c|}{ Smoking index (pack x year) } \\
\hline$<400$ & 260 & $75 \%$ & 291 & $84.10 \%$ & 0.001 \\
\hline $400-800$ & 72 & $21 \%$ & 42 & $12.14 \%$ & \\
\hline$\geq 800$ & 14 & $4 \%$ & 13 & $3.76 \%$ & \\
\hline \multicolumn{6}{|l|}{ Drinking status } \\
\hline no & 204 & $58.96 \%$ & 161 & $46.53 \%$ & 0.001 \\
\hline yes & 142 & $41.04 \%$ & 185 & $53.47 \%$ & \\
\hline \multicolumn{6}{|c|}{ Drinking duration (Drinking years) } \\
\hline$<20$ & 1 & $0.29 \%$ & 50 & $14.45 \%$ & 0.001 \\
\hline $20-35$ & 2 & $0.58 \%$ & 23 & $6.65 \%$ & \\
\hline$\geq 35$ & 129 & $37.28 \%$ & 94 & $27.17 \%$ & \\
\hline \multicolumn{6}{|l|}{ Alcohol intake (g/month) } \\
\hline $1-18$ & 37 & $10.69 \%$ & 6 & $1.73 \%$ & 0.001 \\
\hline $18-90$ & 53 & $15.32 \%$ & 13 & $3.76 \%$ & \\
\hline $91-180$ & 42 & $12.14 \%$ & 148 & $42.77 \%$ & \\
\hline \multicolumn{6}{|c|}{ Alcohol consumption (Alcohol intakex Drinking duration) } \\
\hline 0 & 240 & $69.36 \%$ & 185 & $53.47 \%$ & 0.001 \\
\hline 1 & 80 & $23.12 \%$ & 158 & $45.66 \%$ & \\
\hline 3 & 26 & $7.51 \%$ & 3 & $0.87 \%$ & \\
\hline \multicolumn{6}{|l|}{ Biliary disease } \\
\hline No & 210 & $60.70 \%$ & 344 & $99.4 \%$ & \\
\hline Yes & 136 & 39.30\% & 2 & $0.6 \%$ & \\
\hline
\end{tabular}

Alcohol intake (grams per month) was expressed as grams of alcohol consumption per month

Drinking duration was calculated as years of drinking (drinking years)

Alcohol consumption $=$ Alcohol intake (grams per month) $x$ Drinking duration (drinking years)

\section{Smoking intensity increases the risk for $\mathrm{CP}$}

To evaluate the smoking intensity as a risk factor for $\mathrm{CP}$, the ORs and 95\% CIs for CP in relation to cigarette smoking intensity were calculated using a Cox proportional hazards regression model. The ORs were adjusted for potentially confounding variables, such as age, gender, and biliary disease. The multivariable-adjusted ORs and the corresponding 95\% CI for the risk of CP with respect to smoking intensity are shown in Table 2. CP patients who had smoked more than 20 cigarettes per 
Table 2 Likelihood of chronic pancreatitis with respect to age, gender and biliary disease stratified by smoking intensity (cigarettes per day) in a retrospective case control study

\begin{tabular}{|c|c|c|c|c|c|c|c|c|}
\hline \multirow{4}{*}{ Variable } & \multicolumn{3}{|c|}{ Smoking intensity (cigarettes/d) } & \multirow{4}{*}{$P$ value } & \multicolumn{3}{|c|}{ Smoking intensity (cigarettes/d) } & \multirow{4}{*}{$P$ value } \\
\hline & \multirow{3}{*}{ OR } & & & & \multicolumn{3}{|l|}{$\geq 20$} & \\
\hline & & \multicolumn{2}{|l|}{$95.0 \% \mathrm{Cl}$} & & OR & $95.0 \% \mathrm{Cl}$ & & \\
\hline & & Lower & Upper & & & Lower & Upper & \\
\hline All subjects & 0.779 & 0.424 & 1.431 & 0.421 & 1.595 & 0.979 & 2.598 & 0.061 \\
\hline Male & 0.896 & 0.436 & 1.842 & 0.766 & 1.912 & 1.066 & 3.428 & $0.030^{*}$ \\
\hline Age $\geq 30$ years & 0.851 & 0.45 & 1.61 & 0.62 & 1.663 & 1.012 & 2.732 & $0.045^{*}$ \\
\hline Male, Age $\geq 30$ years & 0.966 & 0.463 & 2.015 & 0.927 & 2.023 & 1.112 & 3.68 & $0.021^{*}$ \\
\hline Male, Age $\geq 30$ years, without biliary disease & 0.926 & 0.371 & 2.311 & 0.87 & 2.11 & 0.951 & 4.684 & 0.066 \\
\hline
\end{tabular}

*have statistical significance Note: Age- and gender-matched healthy individuals were randomly selected from the PUMCH Medical Center as control group

day, and were either male (OR $=1.91,95 \%$ CI: $1.066-$ $3.428, P=0.030)$, or older than 30 years $(\mathrm{OR}=1.66,95 \%$ CI: $1.012-2.732, P=0.045$ ), were significantly more likely to have $\mathrm{CP}$. When all risk factor were combined, in males over 30 years-old, who had additionally smoked more than 20 cigarettes per day, the relative risk of $\mathrm{CP}$ was even higher $(\mathrm{OR}=2.02,95 \% \mathrm{CI}: 1.112-3.68, P=0.021)$. There was no statistically significant association between smoking intensity less than 20 cigarettes per day and the risk of $\mathrm{CP}$ regardless of gender, age, or biliary disease (Table 2).

\section{Smoking duration increases the risk for $\mathrm{CP}$}

The multivariable-adjusted ORs and the corresponding 95\% CI for the risk of CP with respect to smoking duration are shown in Table 3. CP patients, regardless of their gender, who had smoked for more than 30 years and were without biliary disease had a significantly higher risk to develop CP compared with the nonsmoker group $(\mathrm{OR}=2.35,95 \% \mathrm{CI}: 1.106-4.973, P=0.026)$. There was no statistically significant association between smoking duration of less than 30 years and the risk of

Table 3 Likelihood of chronic pancreatitis with respect to gender, biliary disease stratified by smoking duration (in years) in a retrospective case control study

\begin{tabular}{|c|c|c|c|c|c|}
\hline \multirow[t]{2}{*}{ Variable } & \multirow{2}{*}{$\begin{array}{l}\text { Smoking duration } \\
\text { (years) }\end{array}$} & \multirow[t]{2}{*}{ OR } & \multicolumn{2}{|c|}{$95.0 \% \mathrm{Cl}$} & \multirow[t]{2}{*}{$P$ value } \\
\hline & & & Lower & Upper & \\
\hline \multicolumn{6}{|c|}{ All subjects } \\
\hline & $20-29$ & 0.685 & 0.454 & 1.034 & 0.072 \\
\hline & $\geq 30$ & 1.372 & 0.842 & 2.237 & 0.204 \\
\hline \multicolumn{6}{|c|}{ All subjects without biliary disease } \\
\hline & $20-29$ & 0.742 & 0.436 & 1.264 & 0.272 \\
\hline & $\geq 30$ & 2.345 & 1.106 & 4.973 & $0.026^{*}$ \\
\hline \multicolumn{6}{|l|}{ Male } \\
\hline & $20-29$ & 0.655 & 0.405 & 1.06 & 0.085 \\
\hline & $\geq 30$ & 1.32 & 0.723 & 2.412 & 0.366 \\
\hline
\end{tabular}

Age- and gender-matched healthy individuals were randomly selected from the PUMCH Medical Center as control group
$\mathrm{CP}$ regardless of gender, age, or biliary disease (Table 3). ${ }^{*}<0.05$ represents a statistical significance

\section{Discussion}

The present retrospective case-control study revealed that cigarette smoking is an independent risk factor for developing $\mathrm{CP}$ in the Chinese population. Smoking intensity and smoking duration may associated with an increased risk of $\mathrm{CP}$. When the ORs were adjusted for potentially confounding variables, such as age, gender, biliary disease, and alcohol consumption, the relative risk of $\mathrm{CP}$ was even higher in male patients who smoked more than 20 cigarettes per day and were older than 30 years.

Tobacco consumption has been identified as an important risk factor for CP [17, 11, 18-21]. Our current findings in the Chinese population are in line with previous reports in other ethnic groups [25-28, 20,21]. Yen et al. [29] initially reported in 1982 that smoking and drinking habits were independently associated with pancreatitis. The study suggested that cigarette smoking had a much stronger effect than previously anticipated. Subsequently, various studies reported that smoking was a significant risk factor for chronic pancreatitis [25-28, 20, 21]. Wittle et al. [30] provided morphological evidence of pancreatic damage induced by the inhalation of cigarette smoke. The damage is probably mediated by alterations in acinar cell function. Nicotine in smoke affects pancreatic secretion [31,32]. In addition, other constituents in smoke induce inflammatory reaction and carcinogenesis. Further, smoke enhances ethanol-induced pancreatic injury and accelerates the development and progression of CP [30].

Our study showed that the likelihood of CP significantly increases in heavy smokers consistent with previous studies showing an association between cigarette smoking and pancreatitis [20]. Alcohol sensitizes the pancreas to other external risk factors, such as cigarette smoking, nutrition, or genetic predisposition, and together with those factors increases ethanol toxicity in the human body [22]. Talamin et al. [33] revealed an increased relative risk of $\mathrm{CP}$ 
associated with a higher alcohol intake $(P<0.00001)$ or cigarette smoking $(P<0.00001)$. They also noted that there was no significant interaction between alcohol and smoking, which indicates that the two risk factors act independently. The study concluded that males who smoked a higher number of cigarettes daily seemed to be specifically at risk for developing CP. Maisonneuve et al. [18] reported that tobacco smoking significantly increased the risk of pancreatic calcifications with a hazard ratio $\mathrm{HR}$ of 4.9 and $95 \%$ confidence interval $(\mathrm{CI}, 2.3-10.5)$ for smokers compared with non-smokers during the course of pancreatitis. Tobacco smoking was associated with earlier diagnosis of chronic alcoholic pancreatitis and with the appearance of calcifications and diabetes, independent of alcohol consumption \{Maisonneuve, 2005 \#208\}.

There are few epidemiological studies investigating the relationship between $\mathrm{CP}$, smoking, and alcohol consumption. Yen et al. [29] reported that, when ORs were adjusted by age and alcohol consumption, the OR was 10.5 for current smokers, who consumed more than one pack of cigarettes per day. Lowenfels et al. [34] reported that smoking was an additional risk factor for CP (OR 12.5) in male subjects with alcoholic pancreatitis in a native American population. Cigarette smoking was also found to be an independent risk factor for $\mathrm{CP}$ in two case-control studies [21,33], and a cohort study in Finland [28]. These studies further confirmed that smoking is a significant risk factor for CP independent of alcohol consumption.

Our study is the first epidemiological study on smoking as a risk factor for $\mathrm{CP}$ in a Chinese population. There were additional heavy smokers among patients with CP compared with healthy controls. Males, who smoked more than 20 cigarettes per day and were older than 30 years, were at risk of developing $\mathrm{CP}$. These results are consistent with previous studies from other ethnic groups $[29,34]$.

In addition to confirming previous findings, we present new data showing that Chinese male smokers without biliary diseases were more likely to develop CP. This may be due to a larger effect of smoking on alcoholic CP than on other types of $\mathrm{CP}$, since there were more male patients with alcoholic CP in the present study [2, 35]. In other ethnic study populations, the data were mainly collected from patients with alcoholic CP. However, unlike the majority of countries, where alcohol appears to be the major cause of $\mathrm{CP}$, biliary disease is typically one of the primary causes of CP in China [36].

As a retrospective case-control study, the present study has the following limitations. First, some of data may be missing because of deficiencies in the clinical history records. Second, the sample sizes were relatively small, in particular when the subjects were divided into different sub-groups. The third, case control studies can't attribute causality.Therefore, the relatively small sample size may have had negative impact on the level of statistical significance. To overcome these shortcomings, a more comprehensive study enrolling a larger number of subjects and additional data will be conducted.

\section{Conclusion}

In conclusion, cigarette smoking maybe an important risk factor for CP in the Chinese subpopulation. However, whether cigarette smoking and alcohol consumption were associated with the risk for $\mathrm{CP}$ in the Chinese population needs to be determined.

\section{Abbreviations \\ CP: Chronic pancreatitis}

Acknowledgements

None.

Funding

None.

Availability of data and materials

All data generated or analysed during this study are included in this article.

\section{Authors' contributions}

QJM:contributed to the conception of the study. LYM:contributed significantly to analysis and manuscript preparation; $\mathrm{YH}$ and $\mathrm{HW}$ :performed the data analyses and wrote the manuscript; GT, LH and LNN: helped perform the analysis with constructive discussions. All authors read and approved the final manuscript.

\section{Ethics approval and consent to participate}

Written, informed consent was obtained from all individuals enrolled in this study. The study protocol was reviewed and approved by the Institutional Review Committees of Beijing Union Medical College Hospital.

Consent for publication

Not applicable.

\section{Competing interests}

The authors declare that they have no competing interests.

\section{Publisher's Note}

Springer Nature remains neutral with regard to jurisdictional claims in published maps and institutional affiliations.

\section{Author details}

${ }^{1}$ Department of Gastroenterology, Chinese Academy of Medical Sciences and Peking Union Medical College, Peking Union Medical College Hospital, 1 Shuai Fu Yuan, Beijing 100730, China. ${ }^{2}$ The Department of Epidemiology and Biostatistics, Chinese Academy of Medical Sciences and Peking Union Medical College, 5 Dong Dan San Tiao, Beijing 100005, China.

Received: 14 January 2016 Accepted: 20 August 2017 Published online: 25 August 2017

\section{References}

1. Andersen BN, Pedersen NT, Scheel J, Worning H. Incidence of alcoholic chronic pancreatitis in Copenhagen. Scand J Gastroenterol. 1982;17(2):247-52.

2. Spanier B, Bruno MJ, Dijkgraaf MG. Incidence and mortality of acute and chronic pancreatitis in the Netherlands: a nationwide record-linked cohort study for the years 1995-2005. World J Gastroenterol. 2013;19(20):3018-26.

3. Hirota M, Shimosegawa T, Masamune A, Kikuta K, Kume K, Hamada S, et al. The seventh nationwide epidemiological survey for chronic pancreatitis in Japan: clinical significance of smoking habit in Japanese patients. Pancreatology. 2014;14(6):490-6.

4. Y-m L, Guo T, Ding $H$, Lu H, Yang $H$, Yang A-m, et al. Demographic features, etiology trend and clinical characteristics of chronic pancreatitis: a 
retrospective study of 346 cases in Peking union medical college hospital. Med J Peking Union Med Coll Hosp. 2015;6(2):89-95.

5. Brock C, Nielsen LM, Lelic D, Drewes AM. Pathophysiology of chronic pancreatitis. World J Gastroenterol. 2013;19(42):7231-40.

6. Singh S, Kumar R, Choudhuri G, Agarwal S. Chronic pancreatitis: a new pathophysiology. Indian J Hum Genet. 2012;18(3):380-2.

7. Lerch MM, Mayerle J. 50 years of progress in pathophysiology, diagnosis and treatment of chronic pancreatitis. Z Gastroenterol. 2013:51(4):358-62.

8. Trubitsyna IE, Chikunova BZ, Tkachenko EV, Tsaregorodtseva TM, Vinokurova LV, Varvanina GG. Pathophysiology of hormonal, immune, metabolic changes in acute and chronic pancreatitis. Experimental and clinical studies. Eksp Klin Gastroenterol. 2008;7:40-4.

9. Behrman SW, Fowler ES. Pathophysiology of chronic pancreatitis. Surg Clin North Am. 2007;87(6):1309-24.

10. Friess $\mathrm{H}$, Kleeff J, Buchler MW. Molecular pathophysiology of chronic pancreatitis-an update. J Gastrointest Surg. 2003;7(8):943-5.

11. Yadav D, Hawes RH, Brand RE, Anderson MA, Money ME, Banks PA, et al. Alcohol consumption, cigarette smoking, and the risk of recurrent acute and chronic pancreatitis. Arch Intern Med. 2009;169(11):1035-45.

12. Sand J, Lankisch PG, Nordback I. Alcohol consumption in patients with acute or chronic pancreatitis. Pancreatology. 2007;7(2-3):147-56.

13. Papachristou GI, Papachristou DJ, Morinville VD, Slivka A, Whitcomb DC. Chronic alcohol consumption is a major risk factor for pancreatic necrosis in acute pancreatitis. Am J Gastroenterol. 2006;101(11):2605-10.

14. Deng X, Wang L, Elm MS, Gabazadeh D, Diorio GJ, Eagon PK, et al. Chronic alcohol consumption accelerates fibrosis in response to cerulein-induced pancreatitis in rats. Am J Pathol. 2005;166(1):93-106.

15. Toskes PP. Alcohol consumption and chronic pancreatitis. Mayo Clin Proc. 2001;76(3):241

16. Dufour MC, Adamson MD. The epidemiology of alcohol-induced pancreatitis. Pancreas. 2003;27(4):286-90.

17. Law R, Parsi M, Lopez R, Zuccaro G, Stevens T. Cigarette smoking is independently associated with chronic pancreatitis. Pancreatology. 2010;10(1):54-9.

18. Maisonneuve P, Lowenfels AB, Mullhaupt B, Cavallini G, Lankisch PG, Andersen JR, et al. Cigarette smoking accelerates progression of alcoholic chronic pancreatitis. Gut. 2005;54(4):510-4.

19. Pitchumoni CS. Does cigarette smoking cause chronic pancreatitis? J Clin Gastroenterol. 2000;31(4):274-5.

20. Imoto M, DiMagno EP. Cigarette smoking increases the risk of pancreatic calcification in late-onset but not early-onset idiopathic chronic pancreatitis. Pancreas. 2000;21(2):115-9.

21. Lin Y, Tamakoshi A, Hayakawa T, Ogawa M, Ohno Y. Cigarette smoking as a risk factor for chronic pancreatitis: a case-control study in Japan. Research committee on intractable pancreatic diseases. Pancreas. 2000:21(2):109-14.

22. Cavallini G, Talamini G, Vaona B, Bovo P, Filippini M, Rigo L, et al. Effect of alcohol and smoking on pancreatic lithogenesis in the course of chronic pancreatitis. Pancreas. 1994;9(1):42-6.

23. Hartwig W, Werner J, Ryschich E, Mayer H, Schmidt J, Gebhard MM, et al. $2 *$ cigarette smoke enhances ethanol-induced pancreatic injury. Pancreas. 2000; 21(3):272-8.

24. Tandon RK, Sato N, Garg PK, Consensus SG. Chronic pancreatitis: Asia-Pacific consensus report. J Gastroenterol Hepatol. 2002;17(4):508-18.

25. Luaces-Regueira M, Iglesias-Garcia J, Lindkvist B, Castineira-Alvarino M, Nieto-Garcia L, Larino-Noia J, et al. Smoking as a risk factor for complications in chronic pancreatitis. Pancreas. 2014;43(2):275-80.

26. DiMagno MJ, Spaete JP, Ballard DD, Wamsteker EJ, Saini SD. Risk models for post-endoscopic retrograde cholangiopancreatography pancreatitis (PEP): smoking and chronic liver disease are predictors of protection against PEP. Pancreas. 2013;42(6):996-1003.

27. Yadav D, Slivka A, Sherman S, Hawes RH, Anderson MA, Burton FR, et al. Smoking is underrecognized as a risk factor for chronic pancreatitis. Pancreatology. 2010;10(6):713-9.

28. Tolstrup JS, Kristiansen L, Becker U, Gronbaek M. Smoking and risk of acute and chronic pancreatitis among women and men: a population-based cohort study. Arch Intern Med. 2009;169(6):603-9.

29. Yen S, Hsieh CC, MacMahon B. Consumption of alcohol and tobacco and other risk factors for pancreatitis. Am J Epidemiol. 1982;1 16(3):407-14.

30. Wittel UA, Pandey KK, Andrianifahanana M, Johansson SL, Cullen DM, Akhter $M P$, et al. Chronic pancreatic inflammation induced by environmental tobacco smoke inhalation in rats. Am J Gastroenterol. 2006;101(1):148-59.
31. Greer JB, Thrower E, Yadav D. Epidemiologic and mechanistic associations between smoking and pancreatitis. Curr Treat Options Gastroenterol. 2015; 13(3):332-46.

32. Srinivasan $\mathrm{P}$, Thrower EC, Loganathan $\mathrm{G}$, Balamurugan AN, Subramanian VS, Gorelick FS, et al. Chronic nicotine exposure in vivo and in vitro inhibits vitamin B1 (Thiamin) uptake by pancreatic Acinar cells. PLoS One. 2015; 10(12):e0143575

33. Talamini G, Bassi C, Falconi M, Frulloni L, Di Francesco V, Vaona B, et al. Cigarette smoking: an independent risk factor in alcoholic pancreatitis. Pancreas. 1996;12(2):131-7.

34. Lowenfels AB, Zwemer FL, Jhangiani S, Pitchumoni CS. Pancreatitis in a native American Indian population. Pancreas. 1987;2(6):694-7.

35. Mayerle J, Hoffmeister A, Werner J, Witt H, Lerch MM, Mossner J. Chronic pancreatitis-definition, etiology, investigation and treatment. Dtsch Arztebl Int. 2013;110(22):387-93. 10.3238/arztebl.2013.0387.

36. Li JN, Lai YM, Qian JM, Guo T, Lu H, Tang XY. Trends in etiologies of chronic pancreatitis within 20 years: analysis of 636 cases. Chin Med J. 2011;124(21):3556-9.

\section{Submit your next manuscript to BioMed Central and we will help you at every step:}

- We accept pre-submission inquiries

- Our selector tool helps you to find the most relevant journal

- We provide round the clock customer support

- Convenient online submission

- Thorough peer review

- Inclusion in PubMed and all major indexing services

- Maximum visibility for your research

Submit your manuscript at www.biomedcentral.com/submit
Biomed Central 